\title{
A efetividade de medida protetiva de urgência no âmbito da violência doméstica e familiar: o crime de desobediência
}

\section{The effectiveness of injunctions in the familiar and domestic violence framework: the crime of desobediance}

\author{
JAYME WEINGARTNER NETO ${ }^{1}$
}

Desembargador do Tribunal de Justiça do Estado do Rio Grande do Sul

\begin{abstract}
RESUMO: Seguindo a controvérsia jurisprudencial, e na busca de efetividade, o texto defende que o descumprimento de medida protetiva de urgência, decorrente da Lei Maria da Penha, configura crime de desobediência, pela ausência de sanção extrapenal e como reforço sistemático às ações mandamentais de natureza cível.

Palavras-chave: Lei Maria da Penha. Efetividade. Medidas protetivas de urgência. Descumprimento. Crime de desobediência.
\end{abstract}

ABSTRACT: Following the jurisprudential controversy and seeking effectiveness, the text defends that breaches of injunctions - arising from the Maria da Penha Law -, configures crime of disobedience by the absence of non penal sanctions and as systematic reinforcement to the mandatory civil suits.

Keywords: Maria da Penha Law. Effectiveness. Injunction. Breach. Crime of disobedience.

1 CONSIDERAÇÕES INTRODUTÓRIAS

E DELIMITAÇÃO DO TEMA.

A LEI MARIA DA PENHA COMO

RESPOSTA CIVILIZATÓRIA À

VIOLÊNCIA ANCESTRAL

A Lei $\mathrm{n}^{\mathrm{o}}$ 11.340/2006, consagrada como Lei Maria da Penha, dezesseis anos depois, concretizou o mandamento constitucional de tutela e prevenção inserido no $\S 8^{\circ}$ do art. 226 da Constituição Federal, bem como os comandos normativos de hierarquia supralegal (como vem decidindo o STF) da Convenção sobre a Eliminação de Todas as Formas de Discriminação contra as Mulheres e da Convenção Interamericana para Prevenir, Punir e Erradicar a Violência contra a Mulher. E, para cumprir tal desiderato, além de alterar três diplomas gerais (o CP, o CPP e a LEP), o legislador criou o microssistema próprio da Lei Maria da Penha.

Especificamente, seu artigo 22 elencou uma série de medidas protetivas de urgência que o juiz poderá aplicar, de imediato, ao agressor, constatada a prática de violência doméstica e familiar contra a mulher. Estabeleceu-se, desde então, controvérsia jurisprudencial acerca da relevância penal do eventual - e frequente - descumprimento de tais medidas, digladiando-se as correntes entre os que consideram que existe, no caso, crime de desobediência, e entre aqueles que vislumbram atipicidade penal na conduta do agressor renitente. O presente texto, resenhando a polêmica no âmbito das Câmaras Criminais do Tribunal de Justiça do Rio Grande do Sul (2), defende a relevância penal da desobediência em função de dois argumentos principais: a ausência de sanção extrapenal para tais descumprimentos (3) e a necessidade de reforço à efetividade das ações mandamentais de natureza cível. (4) Aproveita-se, também, para esclarecer a adequação típica da conduta desobediente (5) e tecer algumas considerações finais (6).

Antes, porém, considerando que ainda persistem vozes, minoritárias, é bem verdade, a duvidar tanto da bondade da intervenção estatal nesta seara quanto da necessidade de proteção especial, permita-se alinhavar, modo interdisciplinar, fatos que reforçam a legitimidade da solução constitucional e legislativa, a indicar que mesmo o Leviatã primevo, está, ao longo da história, mais para herói do que para vilão.

Discorrendo acerca da violência inerente às sociedades sem Estado, típicas de caçadores-coletores, o neurocientista de Harvard Steven Pinker encontra evidências de que o Leviatã de Hobbes (pese o tom 
pejorativo que adquiriu pelas querelas políticas e filosóficas posteriores), de fato, foi um fator exógeno de pacificação. Mais, esclarece o autor a lógica biológica e psicológica da violência ancestral contra as mulheres, num contexto que ilumina o estado de coisas combatido pela Lei Maria da Penha.

Nas suas palavras:

Também sabemos hoje por que 'esposas' são um dos recursos pelos quais os homens devem competir. Na maioria das espécies animais, a fêmea faz um investimento maior do que o macho na prole. Isso se aplica ainda mais aos mamíferos, pois a mãe gesta a cria dentro do corpo e a amamenta depois do nascimento. Um macho pode multiplicar o número de filhos acasalando-se com várias fêmeas - o que privará outros machos de filhos -, enquanto uma fêmea não pode multiplicar o número de filhos acasalando-se com vários machos. Isso faz da capacidade reprodutiva da fêmea um recurso escasso pelo qual competem os machos de muitas espécies, inclusive a humana. Nada disso, a propósito, implica que os homens sejam robôs controlados por seus genes, que eles possam ser moralmente desculpados por estuprar ou lutar, que as mulheres sejam prêmios sexuais passivos, que as pessoas tentem gerar um maior número possível de bebês ou que sejam impermeáveis a influência de sua cultura, para citar alguns dos equívocos comuns a respeito da teoria da seleção sexual ${ }^{2}$.

Steven Pinker também reuniu uma série de evidências a relacionar a "revolução" por direitos da mulher (no decorrer do século XX) com o declínio de estupros e espancamentos mundo afora. No que interessa mais de perto: "A outra categoria [a primeira é o estupro] relevante da violência contra as mulheres tem sido denominada espancamento conjugal, espancamento, maus tratos maritais, violência entre parceiros íntimos e violência doméstica. O homem usa a força física para intimidar, agredir e, em casos extremos matar a esposa ou a namorada, atual ou ex. Usualmente a violência é motivada por ciúme sexual ou medo de que a mulher iria deixá-lo, embora ela também possa ser usada para estabelecer o domínio masculino na relação, punindo-a por atos de insubordinação com um desafio à autoridade marital, ou um fracasso no cumprimento de um dever doméstico. A violência doméstica é o substrato de uma série de táticas pelas quais os homens controlam a liberdade, especialmente a liberdade sexual, de suas parceiras. Ela pode ser relacionada com o fenômeno biológico de guarda do acasalamento. [...] Nos países ocidentais a década de 1970 assistiu a revogação de muitas leis que tratavam as mulheres com possessão de seus maridos. [...] A maior parte dos
Estados Unidos tem hoje abrigos nos quais uma mulher pode escapar de seu parceiro violento, e o sistema legal reconheceu o direito da mulher à segurança ao criminalizar a violência doméstica. A polícia, que antes ficava fora da 'esfera conjugal', agora é requisitada, na maioria dos estados americanos, para prender um cônjuge caso exista causa provável de maus-tratos. Em muitas jurisdições os promotores são obrigados a buscar medidas cautelares que mantenham um cônjuge potencialmente abusivo longe de seu lar e de seu parceiro, e então de processá-lo sem a opção de retirar a acusação, quer a vítima deseje o prosseguimento, quer não. [...] A Organização Mundial de Saúde recentemente publicou um amontoado de índices de violência doméstica grave de 48 países. Mundialmente, foi estimado que entre um quinto e metade de todas as mulheres já foram vítimas de violência doméstica, e os números são bem piores em países fora da Europa Ocidental e da Anglosfera. [...] As leis sobre violência contra mulheres também mostram um atraso entre as reformas legais nas democracias ocidentais. $\mathrm{Na}$ Europa Ocidental, 84\% dos países criminalizaram ou planejam criminalizar a violência doméstica e $72 \%$ assim agiram em relação ao estupro conjugal. Aqui estão as cifras para outras partes do mundo: Europa Oriental, 57\% e 39\%; Ásia e Pacífico, 51\% e 19\%; América Latina, 94\% e 18\%; África subsaariana, 35\% e 12,5\%; Estados Árabes, 25\% e 0\%. [...] formou-se um consenso no interior da comunidade internacional de que a violência contra mulheres é mais urgente problema de direitos humanos que permanece no mundo.".

Neste contexto, e com olhos na realidade nacional e regional e para concretizar as condições peculiares das mulheres em situação de violência doméstica e familiar (a serem consideradas na interpretação da Lei Maria da Penha, segundo seu artigo 4º), sintetizo alguns aportes sociológicos, primeiro forte em pesquisa do $\mathrm{CNJ}$ : "1. A violência conta a mulher é significativamente expressiva no Brasil, mesmo após o advento da Lei Maria da Penha. O Brasil ocupa o $7^{\mathrm{O}}$ lugar no ranking mundial de homicídios de mulheres. No Brasil ocorrem 4,6 mortes para cada 100 mil mulheres. [...] 3. Do total das mulheres que sofreram agressão física, $48 \%$ delas foram violentadas na própria residência, enquanto $o$ percentual de homens agredidos neste local totalizou 14\%. 4. 41,61\% do total das mulheres brasileiras agredidas foram violentadas no âmbito de suas relações domésticas, afetivas ou familiares, pois o sujeito ativo da agressão foi o cônjuge, o ex-cônjuge ou algum parente. [...] 8. Foram aplicadas, em pouco mais de cinco anos, 280.062 medidas protetivas, considerados os dados de todas as varas e juizados exclusivos do 
País, sendo Rio de Janeiro, Rio Grande do Sul e Minas

Gerais os recordistas em números absolutos."4.

Como segunda fonte, cito o Mapa da Violência 2012 - Atualização: Homicídio de mulheres no Brasil (Julio Jacobo Waiselfisz, agosto de 2012), de cujas considerações finais, extraio: “[...] altos níveis de feminicídio frequentemente vão acompanhados de elevados níveis de tolerância da violência contra as mulheres e, em alguns casos, são o resultado de dita tolerância; se no ano seguinte à promulgação da Lei Maria da Penha - em setembro de 2006 - tanto o número quanto as taxas de homicídio de mulheres apresentaram uma visível queda, já a partir de 2008 a espiral de violência retoma os patamares anteriores, indicando claramente que nossas políticas ainda são insuficientes para reverter a situação". Observo, ainda, que o Rio Grande do Sul encontra-se em 19ํㅡㄹ entre os Estados do país, com taxa de homicídio feminino de 4,1 homicídios em cada 100 mil mulheres. Porto Alegre ocupa a $8^{\text {a }}$ posição entre as capitais de Estados, com taxa de 6,6. Quanto às violências físicas, "acontecem de forma preponderante no domicílio das vítimas e, entre os 10 e os 30 anos de idade, também na via pública. Pais, até os 9 anos de idade, e parceiros, a partir dos 20 e até os 50 anos de idade, revezam-se como principais agentes dessas violências físicas. A partir dos 60 anos de idade da mulher, vão ser os filhos que assumem papel de destaque." ${ }^{\text {. }}$

Delimitado o tema e justificada sua relevância, apresento, no próximo segmento, o estado da arte da jurisprudência relacionada ao tema em apreço na Corte gaúcha.

\section{A CONTROVÉRSIA JURISPRUDENCIAL NO ÂMBITO DO TRIBUNAL DE JUSTIÇA DO RIO GRANDE DO SUL}

A jurisprudência majoritária das Câmaras Criminais com competência específica do Tribunal de Justiça do Rio Grande do Sul, orienta-se pela atipicidade da conduta prevista no artigo 330, caput, do Código Penal (ou do art. 359 do mesmo diploma legal) quando o ato de desobediência caracterizar o descumprimento de medida protetiva imposta nos termos da Lei 11.340/06. Apenas para ilustrar:

APELAÇÃO-CRIME. VIOLÊNCIADOMÉSTICA. DESCUMPRIMENTO DE MEDIDA PROTETIVA. DELITO DE DESOBEDIÊNCIA. ATIPICIDADE. DENÚNCIA REJEITADA. O descumprimento de medidas protetivas não caracteriza o delito de desobediência, pois a própria Lei Maria da Penha prevê sanção específica quando tal ocorrer.
Apelo improvido. Unânime. (Apelação Crime $\mathrm{n}^{\mathrm{o}}$ 70050602887, Quarta Câmara Criminal, Tribunal de Justiça do RS, Relator: Aristides Pedroso de Albuquerque Neto, Julgado em 04/10/2012).

APELAÇÃO CRIMINAL. VIAS DE FATO, LESÕES CORPORAIS, CÁRCERE PRIVADO E AMEAÇA. MATERIALIDADE E AUTORIA DEVIDAMENTE COMPROVADAS. CONDENAÇÃOQUESEIMPUNHA.DESOBEDIÊNCIA.O DESCUMPRIMENTO DE MEDIDA PROTETIVA IMPOSTA EM RAZÃO DA LEI MARIA DA PENHA POSSUI CLÁUSULA RESOLUTIVA PRÓPRIA, CONSISTENTE NA PRISÃO PREVENTIVA DO INFRATOR. O AGENTE QUE DESOBEDECE A MEDIDA PROTETIVA JÁ FOI NOTIFICADO PREVIAMENTE DE QUE SEU COMPORTAMENTO IMPORTARÁ EM PRISÃO. ASSIM, NÃO HÁ A DESOBEDIÊNCIA NA FORMA PREVISTA NOS ARTS. 330 OU 359 DO CÓDIGO PENAL, MAS SITUAÇÃO QUE IMPLICA NA OBSERVÂNCIA DA SANÇÃO RESPECTIVA PREVISTA NA LEI № 11.340/06. Apelo parcialmente provido. (Apelação Crime $\mathrm{n}^{\mathrm{O}}$ 70040074163, Primeira Câmara Criminal, Tribunal de Justiça do RS, Relator: Manuel José Martinez Lucas, Julgado em 27/04/2011).

APELAÇÃO CRIME. VIOLÊNCIADOMÉSTICA. DESOBEDIÊNCIA. DESCUMPRIMENTO DE MEDIDA PROTETIVA. ATIPICIDADE DA CONDUTA. ABSOLVIÇÃO. Não caracteriza o crime de desobediência, previsto no artigo 330 do Código Penal, o descumprimento de medida protetiva deferida com base na Lei Maria da Penha. As medidas protetivas previstas na Lei 11.340/06 são medidas cautelares, que visam proteger as vítimas de abuso por parte de seus agressores. Tais medidas são progressivas, podendo evoluir até a prisão preventiva do agente, caso as medidas mais brandas se mostrem insuficientes para proteger a vítima. AMEAÇA. PROVA. PALAVRA HARMONICA DA VÍTIMA. SUFICIÊNCIA. CONDENAÇÃO MANTIDA. Pratica o crime de ameaça o agente que, insatisfeito com a separação do casal, passa a intimidar sua ex-companheira de mal injusto, desobedecendo as medidas protetivas deferidas e acaba ameaçando-a de mal injusto. Ao contrário do que sustenta a defesa, a prova é suficiente para a convicção condenatória. A palavra da vítima, coerente e harmônica, serve para embasar o decreto condenatório. EMBRIAGUEZ. ATIPICIDADE DA CONDUTA. INOCORRÊNCIA. A embriaguez voluntária não exclui a imputabilidade penal do agente. A embriaguez somente é causa de isenção de responsabilidade penal ou de redução de pena, quando involuntária, decorrente de caso fortuito ou 
força maior, nos termos do artigo 28 , parágrafos $1^{\mathrm{o}}$ e $2^{\underline{Q}}$, do Código Penal, o que não ocorreu no caso dos autos. PENA RESTRITIVA DE DIREITOS. Condenado que ostenta condições subjetivas que obstam a possibilidade de substituição da pena detentiva por restritivas de direitos. PARCIAL PROVIMENTO. (Apelação Crime no 70044572469, Primeira Câmara Criminal, Tribunal de Justiça do RS, Relator: Marco Antônio Ribeiro de Oliveira, Julgado em 14/09/2011).

Todavia, a matéria não se encontra pacificada ainda, o que se pode verificar das decisões em sentido contrário, que admitem o crime de desobediência na hipótese em comento. Também por amostragem, Apelação Crime no 70044879112, Quarta Câmara Criminal, Rel. Des. Marcelo Bandeira Pereira, j. em 13/10/2011; Apelação Crime no 70031074883 , Primeira Câmara Criminal, Rel. Des. Marco Antônio Ribeiro de Oliveira, j. em 09/9/2009; Embargos Infringentes oㅡ 70037922218, Segundo Grupo Criminal, Rel. Marcelo Bandeira Pereira,j. em 10/9/2010. Mais recentemente, Apelação Crime no 70050937861, Terceira Câmara Criminal, Rel. Des. Jayme Weingartner Neto, j. em 22/11/2012. Quanto ao último aresto, de minha relatoria, pendem Embargos Infringentes no 70053236998, Rel. Des. Gaspar Marques Batista. Aliás, a última decisão de que tenho notícia (Embargos Infringentes e de Nulidade no 70053114211, Primeiro Grupo Criminal, j. em 05/4/2013) apenas confirma a controvérsia, acolhidos os embargos por maioria mínima - para reafirmar que o descumprimento de medida protetiva possui cláusula resolutiva própria (prisão preventiva do infrator), pelo que não há desobediência -, vencidos os Des. Canosa, Lizete e Finger, redator para o acórdão o Des. Manuel José Martinez Lucas.

Outrossim, a doutrina e a jurisprudência, notadamente do STJ, têm entendido pela atipicidade do crime de desobediência quando houver norma extrapenal a cominar, para o mesmo fato, sanção civil ou administrativa ${ }^{6}$.

Confira-se:

RHC. TRANCAMENTO. AÇÃO PENAL. CRIMES DE DESOBEDIÊNCIA E PECULATO. LEILOEIRO. DEVOLUÇÃO. COMISSÃO.

1. Não resta configurado o delito de desobediência quando lei de conteúdo extrapenal, da qual decorre sanção administrativa ou civil, não prevê, expressamente, a possibilidade de aplicação cumulativa do art. 330 do Código Penal.

2. Não há falar em peculato se não está definida, na esfera cível, a obrigatoriedade da devolução de verba - comissão paga pelo arrematante ao leiloeiro no valor de 5\% sobre o lance aceito - que lhe era devida legitimamente.

3. Recurso ordinário provido para trancar a ação penal.

(RHC 12.321/SP, Rel. Ministro FONTES DE ALENCAR, Rel. p/ Acórdão Ministro FERNANDO GONÇALVES, SEXTA TURMA, julgado em 05/09/2002, DJ 29/09/2003, p. 351).

$\mathrm{O}$ argumento, em síntese, para a corrente que vislumbra atipicidade da conduta na hipótese em tela, é que as medidas protetivas previstas na Lei $\mathrm{n}^{\mathrm{o}}$ 11.340/06 são medidas cautelares progressivas, podendo evoluir até a prisão preventiva do agente, caso as medidas mais brandas se mostrem insuficientes para a proteção da vítima.

Estabelecido, em linhas gerais, o quadro jurisprudencial, nos itens seguintes justifico meu posicionamento ${ }^{7}$.

\section{PELA TIPICIDADE PENAL: O ARGUMENTO DA AUSÊNCIA DE SANÇÃO EXTRAPENAL}

O que se está a ponderar, concorde com a progressividade da medida cautelar, é que para desobediência de medida protetiva de urgência, deferida nos termos da Lei Maria da Penha, não há sanção, propriamente dita, cominada.

O que há, sim, é possibilidade de decretação da prisão preventiva, nos termos do artigo 313 , inciso III, do CPP, e submetida aos requisitos do art. 312 do mesmo diploma legal. Mas prisão preventiva, como se sabe, não é sinônimo de sanção, como bem vem diferenciando a jurisprudência hodierna.

E se, portanto, não há sanção extrapenal prevista para desobediência de medida protetiva (e sim apenas providência acauteladora), a conduta de desobedecer ordem judicial que visa a proteger vítimas de violência doméstica permanece hígida em sua tipicidade.

Observo, ainda, que a tendência jurisprudencial atual, mormente em face da falência do sistema prisional e de alguns abusos na utilização da custódia provisória, parece caminhar no sentido de mitigar as possibilidades de prisão preventiva para os delitos de violência doméstica ou familiar, até mesmo pelo quantum de pena previsto abstratamente para esses crimes e na esteira da excepcionalidade da segregação propagada pelo Supremo Tribunal Federal.

Destarte, conceber como atípica a conduta de desobedecer medida protetiva de urgência, levando em conta a excepcional segregação cautelar para os crimes 
relacionados à violência doméstica, seria - renovando venia aos que pensam diversamente - aumentar a vulnerabilidade da mulher, bem como a sensação de impunidade do agressor, esvaziando a própria ratio da Lei 11.340/06 e, no limite, do $\S 8^{\circ}$ do art. 226 da Constituição Federal.

De salientar, ainda, que, mesmo diante da previsão do inciso III do artigo 313 do CPP, é imprescindível para a segregação cautelar o preenchimento dos requisitos do artigo 312 do mesmo diploma legal. Assim, nos casos em que não presente concreta violação à ordem pública ou econômica, necessidade de assegurar a aplicação da lei penal ou por conveniência da instrução criminal, não caberá a prisão preventiva, já que não se pode admiti-la pela simples violação das medidas protetivas de urgência.

Deste modo, as possibilidades de prisão cautelar, nos crimes abrangidos pela Lei 11.340/06 - como, de resto, em geral, já que a liberdade é a regra, e a prisão, exceção -, afiguram-se cada vez mais exíguas, o que acaba por acarretar uma situação não desejada de lacuna de impunidade para aquele que desrespeita os comandos judiciais, demonstrando descaso com o próprio Poder Judiciário. E, aqui, uma nótula: o poder, no Estado democrático de direito, por óbvio, não está à disposição do Senhor, para ser abusado. Mas deve ser exercido, pela Autoridade, em prol da democracia e do direito, sem qualquer pudor ou hesitação. A autoridade legítima deve ser respeitada, primado do Estado Constitucional, que, hoje, muito longe está do Leviatã que precisava ser amordaçado e contido pelo nascente liberalismo, exasperado pela configuração monárquico-absolutista da primeira fase histórica de formação do Estado moderno.

\section{PELA TIPICIDADE PENAL: REFORÇO SISTEMÁTICO ÀS AÇÕES MANDAMENTAIS DE NATUREZA CÍVEL}

Por outro lado, em linha adicional de argumentação, traço uma ponte sistemática com o direito processual civil, seara donde emanam as medidas (cautelares) protetivas de urgência no âmbito doméstico e familiar. À luz do art. 22 da Lei no 11.340/06, é possível alinhar outro topoi pela tipicidade do crime de desobediência em casos como o da espécie.

Modernizada a tradicional classificação trinária das ações no processo civil, por construção doutrinária, hodiernamente entende-se instituída a teoria quinária da ação, compreendendo, dentro do gênero ação de conhecimento, cinco espécies de tutela: declaratória, condenatória, constitutiva, executiva lato sensu e mandamental. Esta última categoria, que é a que por ora interessa, visa a dar maior efetividade à tutela jurisdicional; por ela, o Magistrado impõe ordem direta ao destinatário (obrigação de facere ou non facere) da decisão, coagindo-o a cumpri-la sob pena de coerção pessoal e até eventual materialização de crime de desobediência. É o caso, aliás, do mandado de segurança, no qual a sentença de procedência contém ordem para cessação ou adequação da atuação da autoridade coatora, sob pena de caracterização de desobediência. Em outras palavras, na tutela mandamental, a resistência à ordem judicial poderá caracterizar ilícito penal de desobediência.

Insisto, a progressividade das medidas protetivas, embora razoável postulado, não deflui da técnica redacional do art. 22 da Lei no 11.340/06. A “evolução até a prisão cautelar" submete-se não à lógica do descumprimento em si, mas aos requisitos cautelares do processo penal (arts. 311 e 312 do CPP), filtro extremamente rigoroso que deixa escorrer uma série de descumprimentos. Neste contexto, o direito penal, como ultima ratio, é chamado, a posteriori, para consubstanciar eficácia ao comando constitucional do $\S 8^{\mathrm{o}}$ do art. 226, pena de atuação deficiente do Estado. Ademais, o $\S 1^{\mathrm{o}}$ do art. 22 em comento, na leitura que faço, expressamente permite a cumulatividade sancionatória, pois as medidas elencadas "não impedem a aplicação de outras previstas na legislação em vigor, sempre que a segurança da ofendida ou as circunstâncias o exigirem".

Desta forma, como bem leciona a doutrina ${ }^{8}$, "a mandamentalidade entra como técnica legislativa de apoio, em casos patológicos, ao princípio constitucional que obriga o Estado a conceder adequados meios de tutela às situações em que se alega lesão ou ameaça de lesão a direito (art. 5ำ, inciso XXXV, da Constituição Federal) - isto, para afastar antigos preconceitos restritivos que impediam a consecução dos exatos objetivos visados pelo direito material. [...] nas ações mandamentais a atividade jurisdicional está direcionada à emissão de uma ordem determinando que o próprio destinatário pratique o ato ordenado, sob pena da incidência de elementos coercitivos diretos que poderão ter consequências sobre a própria pessoa do destinatário da ordem. Trata-se da possibilidade da resistência à ordem judicial caracterizar ilícito penal de desobediência.". Claro, pois, do contrário, em vez de ordeno, o magistrado faria constar exorto, recomendo. Noutras palavras, mais uma via de concretização de um direito fundamental à tutela jurisdicional adequada e efetiva, quando o objeto da ação não se coaduna com a conversão em perdas e danos.

Assim, com a presença do elemento mandamental, mormente nas medidas protetivas de urgência, a dúvida 
do destinatário da determinação judicial de afastamento do lar no âmbito da Lei Maria da Penha, entre aceitar ou resistir à decisão, passa a ser pautada, não só pelos elementos intrinsecamente relacionados com a questão, mas também pela extrema pressão subjetiva que vai representada pela ameaça de perda de outros direitos e, até mesmo, da própria liberdade em decorrência da responsabilização penal pelo delito de desobediência.

E não se está diante da vedação constitucional (art. 5ㅇ, LXVII, da CF) de sanção penal decorrente de relação cível, pois este não alcança o desprezo à dignidade da Justiça ou atos que embaracem o exercício regular da jurisdição. Pertinente, nesse quadro, trazer a lume o direito comparado, nomeadamente o direito anglo-americano, cujos ordenamentos são filiados à Common Law. Refiro-me aos institutos da injuction e do contempt of court.

As injuctions são medidas consistentes na imposição de um dever de praticar determinado ato por força de uma determinação judicial, sob pena de, coercitivamente, reprimir-se eventual resistência. E, nesta senda, o ordenamento jurídico brasileiro vem buscando alternativas que garantem maior efetividade para o sistema processual, caminho que passa pela crescente utilização das tutelas mandamentais.

A atividade jurisdicional deve atingir, dentre outros, o escopo de afirmar o poder e a preponderância das decisões, ditados pela política do Estado (que é democrático de direito, nos termos do caput do art. $1^{\circ}$ da CF), o chamado escopo político. Para tanto, o julgador deve, no desempenho de sua atividade típica, dispor de instrumentos processuais necessários ao cumprimento das determinações judiciais. Nesse desiderato, é que no sistema da Common Law afigura-se o instituto do contempt of court, intimamente ligado à necessidade de repressão dos atos das partes que estejam impedindo o bom desempenho da função jurisdicional ou permitindo um descabido e injustificado descumprimento da decisão do Magistrado. Assim, a doutrina define o contempt of court como "qualquer ato ou omissão que tenda a dificultar a administração da justiça pelo juízo ou que diminua sua autoridade ou dignidade" 9 . Trata-se de instituto de natureza pública destinado a assegurar a eficácia da tutela jurisdicional.

Como é possível perceber, do cotejo doutrinário referido e dos arts. 22 a 24 da Lei Maria da Penha supra-alinhados, a tendência processual contemporânea, representada pela tutela mandamental, é de afirmar a necessidade de coerção em relação aos provimentos judiciais, buscando dar maior efetividade à tutela jurisdicional. Assim é que, retirada a coerção exercida sobre o indivíduo que não obedece medida protetiva de urgência (espécie de decisão dotada de mandamentalidade), consubstanciada na tipificação de sua conduta no crime de desobediência, arrisca-se, em uma análise sistemática do ordenamento jurídico pátrio, a esvaziar a própria eficácia das decisões do Juiz, evidente a onda negativa de reflexos dentro do Poder Judiciário e na própria sociedade.

Reparo, em acréscimo, que o $\S 4^{\circ}$ do art. 22 da Lei Maria da Penha remete o regime das medidas protetivas para o caput e $\S \S 5^{\circ}$ e $6^{\circ}$ do art. 461 do Código de Processo Civil, que veio justamente (no bojo das reformas do Processo Civil em busca de efetividade, ainda em 1994) a reforçar a tutela específica das obrigações de fazer ou não fazer.

Ainda, socorrendo-me novamente no direito comparado, a doutrina portuguesa, ao comentar o artigo $348^{\circ}$ do Código Penal luso, crime de desobediência, esclarece: "questão que se põe frequentemente é a de saber se integra ou não a previsão deste artigo o não cumprimento de decisões judiciais, ponto sobre o qual existe abundante jurisprudência. De um modo geral, e quando não há lei especial a regular o caso, deve afirmar-se que só quando as decisões judiciais contêm ordens específicas, de facere ou de non facere, máxime nas providências cautelares, o seu não cumprimento integra o crime de desobediência." 10 .

\section{NOTA EM PROL DA ADEQUAÇÃO TÍPICA: ARTIGOS 330 OU 359 DO CÓDIGO PENAL}

Percebe-se, na prática forense, seja nas denúncia, nas sentenças ou até em acórdãos, certa hesitação no que tange ao correto enquadramento do crime praticado quando descumprida medida protetiva de urgência, ora imputando-se o delito previsto no art. 330 do Código Penal, ora preferindo-se o crime descrito no artigo 359 do Código Penal. Sem pretensão de esgotar o tema, creio que não são categorias permutáveis.

Na lição de NUCCI:

\begin{abstract}
as medidas restritivas, previstas na Lei de Violência Doméstica (art. 22, II e III, Lei 11.340/06), proibindo o marido ou companheiro de se aproximar da mulher ou determinando o seu afastamento do lar constituem ordens judiciais. Logo, nesses casos, se descumpridas, acarretam o crime de desobediência (art. 330, CP). Não se configura o delito do art. 359, pois a situação de marido ou companheiro não constitui função, atividade, direito, autoridade ou múnus ${ }^{11}$.
\end{abstract}

Aprofundando, penso que análise sistemática do artigo 22 da Lei Maria da Penha leva à conclusão seguinte: 
1. o descumprimento das medidas protetivas elencadas nos seus incisos II e III implica crime geral de desobediência (art. 330 do CP), eis que substanciam obrigações de fazer ou não fazer - o que se verifica pela leitura dos verbos (afastar-se, inc. II, facere; proibição de condutas, inc. III, como: não se aproximar, 'a', não contatar, 'b', não frequentar, 'c', non facere);

2. o descumprimento das medidas protetivas previstas nos incisos I e IV importa em crime específico de desobediência a decisão judicial sobre perda ou suspensão de direito (art. 359 do Código Penal), pois presentes suspensão/restrição de direitos: de porte de arma (inc. I) e de direito de visita, regulado no âmbito do direito de família (inc. IV);

3. finalmente, o descumprimento da medida protetiva constante do inc. V do art. 22 é atípico penal, já que o inadimplemento de prestação alimentícia resolve-se pela execução nos termos do art. 733 do Código de Processo Civil, autorizada excepcionalmente a prisão civil por dívida (CF, art. 5을 inc. LXVII).

\section{CONSIDERAÇÕES FINAIS}

Não se pode, portanto, definir aprioristicamente pela atipicidade do crime de desobediência quando se tratar de descumprimento de medida protetiva de urgência, devendo a análise e sopesamento das peculiaridades do caso concreto demonstrar a necessidade da punição pelos delitos previstos nos artigos 330 ou 359 do CP, sob pena de o violador da norma quedar-se em um limbo jurídico de ausência de punição, verdadeiro bill de indenidade, se escapar da excepcionalíssima prisão preventiva, de natureza processual.

Soma-se a isso o fato de que, enquanto a prisão preventiva deflagrada pela Lei Maria da Penha tem o desiderato de prevenir a continuidade das agressões contra a mulher, evitando consequências por vezes irreparáveis, o crime de desobediência, praticado por particular contra a Administração Pública ou contra a Administração da Justiça, tutela o prestígio e a dignidade do Estado, sendo este diretamente atingido pelo delito.

Ademais, o dever reforçado que o poder público tem de resguardar as mulheres da violência (dever constitucional de proteção e proibição de atuação deficiente), no âmbito das relações domésticas e familiares (art. $3^{\circ}$, $\S 1^{\circ}$, da Lei $n^{\circ}$ 11.343/2006), engloba a técnica de tutela inibitória, com o reforço penal às ações mandamentais. Ainda, o princípio da máxima eficácia dos direitos fundamentais $(\mathrm{CF}$, art. 5을 $\S 1^{\circ}$ ) especifica-se no dever de o poder público criar as condições necessárias para o efetivo exercício dos direitos em tela ( $§ 2^{\circ}$ do art. $3^{\circ}$ da Lei Maria da Penha) e na diretriz hermenêutica de sopesar os fins sociais colimados e as peculiares condições (já citadas no item 1) das mulheres em situação de violência doméstica e familiar (art. 4을 da Lei Maria da Penha).

Por fim, derradeiro argumento, a um tempo pragmático e consequencialista. Indaga-se: de que maneira seria coibido o descumprimento das medidas protetivas, caso não configurasse desobediência? Como prender em flagrante o perpetrador, justo na antecipação de tutela preconizada e possibilitada pela Lei Maria da Penha, exatamente na linha (meritória, acredito), das patrulhas e rondas organizadas pela polícia militar, se descumprir medida protetiva não é crime? Ou o Poder Judiciário determinará, ao concluir pela atipicidade da desobediência, que os agentes policiais assumam o risco de eventual abuso de autoridade? Ou será obrigação adicional da vítima comunicar o juízo que, então sim, para garantir a efetividade das medidas protetivas de urgência, poderá requisitar auxílio da força policial (art. 22, § 3oㅡㄹ da Lei Maria da Penha)? Em suma, também por bom senso, a realidade dos fatos tensiona o entendimento de que a eventual "sanção" processual cautelar (expressão que soa paradoxal, pois não se trata de antecipação de pena) é causa obstativa de tipificação do crime de desobediência.

\section{REFERÊNCIAS}

GONÇALVES, M. Maia. Código Penal português, anotado e comentado e legislação complementar. Coimbra: Almedina, 1999.

NUCCI, Guilherme de Souza. Código de Penal comentado. 11. ed. São Paulo: Revista dos Tribunais, [20??]. p. 1279.

PINKER, Steven. Os anjos bons da nossa natureza. Por que a violência diminuiu. São Paulo: Companhia das Letras, 2013.

PUOLI. José Carlos Baptista. Os poderes do juiz e as reformas do processo civil. São Paulo: Editora Juarez de Oliveira, 2001.

\section{NOTAS}

${ }^{1}$ Mestre (Coimbra) e Doutor em Direito (PUCRS). Professor do PPG em Direito da UNILASSALE.

2 “[...] A análise de Hobbes diz respeito à vida em estado de anarquia [estado de natureza]. O título de sua obra prima identificou um modo de escapar dela: o Leviatã, uma monarquia ou outra autoridade governamental que incorpora a vontade do povo e tenha o monopólio do uso da força. Aplicando penalidade aos agressores, o Leviatã pode eliminar o incentivo para a agressão, o que elimina as preocupações gerais sobre ataques preventivos e a necessidade de que cada um se mantenha sempre pronto para retaliar à menor provocação de modo a provar sua determinação. $\mathrm{E}$ 
como o Leviatã é uma terceira parte desinteressada, não sofre influências do chauvinismo que faz cada lado pensar que seu oponente tem um coração das trevas em comparação com o seu, que é puro como um cristal. A lógica do Leviatã pode ser resumida em um triângulo. Em cada ato de violência há três partes interessadas: o agressor, a vítima e um observador. Cada um tem um motivo para a violência: o agressor, predar a vítima; a vítima, retaliar; o observador, minimizar os danos colaterais da luta dos dois. A violência entre os combatentes pode ser chamada guerra; a violência do observador contra os combatentes pode ser chamada lei. A teoria do Leviatã, em resumo, diz que a lei é melhor do que a guerra. A teoria de Hobbes faz uma previsão que pode ser testada sobre a história da violência.”. - PINKER, Steven. Os anjos bons da nossa natureza. Por que a violência diminuiu. São Paulo: Companhia das Letras, 2013, p. 70 e 72, respectivamente - grifei. Adiante (p. 88-99), com base em dados empíricos rigorosos e cotejando percentuais de mortes em guerra de caçadores-coletores e outros grupos tribais e sociedades com Estado, o autor constata que, mantidos constantes muitos fatores, "viver na civilização reduz em cinco vezes as chances de uma pessoa ser vítima de violência" (p. 93).

3 PINKER, Os anjos bons da nossa natureza, p. 552, 553, 560, 561, respectivamente - gizei. Nas suas conclusões gerais, o autor consigna: "Portanto, muitas variedades de feminização - empoderamento político direto, deflação da honra viril, promoção do casamento nos termos da mulher, direito de nascer das meninas e controle das mulheres sobre sua própria reprodução - foram forças motrizes da redução da violência.
As partes do mundo que se atrasam nessa marcha histórica são as que se atrasam no declínio da violência." (idem, p. 916, destaquei).

4 A atuação do Poder Judiciário na aplicação da Lei Maria da Penha Sumário Executivo, Departamento de Pesquisas Judiciárias do Conselho Nacional de Justiça, disponível em < http://www.cnj.jus.br/pesquisas-judi ciarias/2011-08-10-19-36-05>, acesso em 13/06/2013. Registro, em face dos números, a extraordinária repercussão quanto a considerar típica ou não a desobediência a tais medidas de proteção.

${ }^{5}$ Disponível em <http://mapadaviolencia.org.br/pdf2012/mapa2012 mulher.pdf $>$, acesso em 13/06/2013.

${ }^{6}$ E tal entendimento parece lógico, tendo sido por mim adotado por ocasião do julgamento da apelação 70048860571 (julgada na Terceira Câmara Criminal na sessão do dia 08/11/2012), que versava sobre delito de trânsito e infração administrativa.

${ }^{7}$ Originalmente exposto na Apelação Crime n ${ }^{0} 70050937861$, citada no item 2.

${ }^{8}$ PUOLI. José Carlos Baptista. Os poderes do juiz e as reformas do processo civil. São Paulo: Editora Juarez de Oliveira, 2001, p. 124 e 112 , respectivamente.

9 PUOLI, Os poderes do juiz e as reformas do processo civil, p. 121.

${ }^{10}$ GONÇALVES, M. Maia. Código Penal português, anotado e comentado e legislação complementar. Coimbra: Almedina, 1999, p. 924.

11 NUCCI, Guilherme de Souza. Código de Penal comentado. 11. ed. São Paulo: Revista dos Tribunais, p. 1279. 